Check for updates

Cite this: Chem. Commun., 2021, 57,8600

Received 27th June 2021 Accepted 31st July 2021

DOI: $10.1039 / \mathrm{d} 1 \mathrm{cc} 03418 \mathrm{a}$

rsc.li/chemcomm

\section{Supported permethylindenyl titanium catalysts for the synthesis of disentangled ultra-high molecular weight polyethylene (disUHMWPE) $\uparrow$}

\author{
Clement G. Collins Rice, (D) Jean-Charles Buffet, (D) Zoë R. Turner (D) and \\ Dermot O'Hare (iD *
}

\begin{abstract}
Novel permethylindenyl-phenoxide (PHENI*) ansa-metallocene titanium complexes have been synthesised and immobilised on inorganic solid supports to afford highly effective catalysts for slurry-phase ethylene polymerisation. When supported on solid polymethylaluminoxane these complexes were both extremely active (up to $3.7 \times 10^{6} \mathrm{~g}_{\mathrm{PE}} \mathrm{mol}_{\mathrm{Ti}}{ }^{-1} \mathrm{~h}^{-1}$ bar $^{-1}$ ) and produced substantially disentangled polyethylene with a weight-average molecular weight $\left(M_{w}\right)$ of 3.4 MDa (disUHMWPE).
\end{abstract}

Group 4 metallocenes are a key alternative to traditional heterogeneous Ziegler-Natta and Philips catalysis in the polymerisation of olefins. Kaminsky catalysts - metallocenes activated with methylaluminoxane (MAO) - are homogeneous, exhibit singlesite behaviour, and are used in applications where fine control of the polymer molecular weight and distribution, co-monomer content and microstructure are required. ${ }^{1}$

Kaminsky metallocene catalysts are commonly immobilised on solid inorganic supports to facilitate large-scale industrial applications. This approach combines the advantages of controllable single-site homogeneous catalysis with the industrially desirable process engineering of heterogeneous systems. Supports used in this context have included those based on silica, ${ }^{2}$ alumina, ${ }^{3}$ and zirconia. ${ }^{4}$ Recently, we have reported layered double hydroxides (LDHs) synthesised using an aqueous miscible organic solvent treatment method as slurry-phase polymerisation supports..$^{5-7}$ Solid polymethylaluminoxane (solid MAO, sMAO) is a partially hydrolysed, hexane-insoluble form of MAO which does not require modification to act as an activating catalyst support and has been shown to produce polymers with narrow molecular weight distributions and single-site catalysis performance profiles. ${ }^{8-10}$

Department of Chemistry, Chemistry Research Laboratory, University of Oxford, 12 Mansfield Road, Oxford, OX1 3TA, UK. E-mail: dermot.ohare@chem.ox.ac.uk $\dagger$ Electronic supplementary information (ESI) available: Experimental procedures, X-ray data, NMR data, polymerisation data. CCDC 2090028. For ESI and crystallographic data in CIF or other electronic format see DOI: 10.1039/ d1cc03418a
Recent developments in post-metallocene catalysts include constrained geometry complexes (CGCs) and Phenoxy-Induced Complexes of Sumitomo (PHENICS). CGC is a term originally describing ansa-cyclopentadienyl-amido complexes but now encompasses a wide variety of related isolobal systems based on transition metals and the lanthanides, many of which show exceptional activity towards polyolefin synthesis. ${ }^{11,12}$ PHENICS is a more recent technology, employing ansa-cyclopentadienylphenoxide ligands, developed by Sumitomo Chemical Co., Ltd. (Japan). Initial studies on ethylene-1-hexene copolymerisation indicate that PHENICS catalysts are highly active and produce high molecular weight polymers. An improvement in activity is reported over CGC catalysts, particularly at high temperature, with single-site catalytic behaviour maintained above $200{ }^{\circ} \mathrm{C}$. ${ }^{13-16}$

Herein, we report the efficient synthesis of a new family of permethylindenyl $\left(\mathrm{Ind}^{*}, \mathrm{I}^{*}\right.$ ) phenoxide $\left(\mathrm{PHENI}^{*}\right)$ ansa-metallocenes, and their subsequent immobilisation on various inorganic supports (silica, LDH, and SMAO) to afford highly active solid catalysts. We report their use in slurry-phase polymerisation of ethylene, with extremely high activities, desirable polymer morphology, and the production of ultra-high molecular weight polyethylene (UHMWPE, $M_{\mathrm{w}}>1 \mathrm{MDa}$ ). UHMWPE finds applications principally in biomedical implants where its high impact strength, low coefficient of friction and resistance to mechanical wear and chemical corrosion are highly desirable. ${ }^{17} \mathrm{~A}$ significant hindrance to the usefulness of UHMWPE is its extremely high melt viscosity which does not allow for common processing techniques such as injection moulding. ${ }^{18}$ Single-site post-metallocenes have been demonstrated to produce UHMWPE having significantly reduced chain entanglement density which can then be processed in the solid state below the melting temperature. ${ }^{19-21}$

Chlorosilanes, $\mathrm{Me}_{2} \mathrm{Si}\left({ }^{\mathrm{R}_{1} \mathrm{R}_{2}}\right.$ ArOAllyl $) \mathrm{Cl}\left({ }^{\mathrm{R}_{1} \mathrm{R}_{2}}\right.$ ArOAllyl, 2- $\mathrm{R}_{1}-4-\mathrm{R}_{2}-$ $\mathrm{C}_{6} \mathrm{H}_{2} \mathrm{OCH}_{2} \mathrm{CHCH}_{2}$ where $\mathrm{R}_{1}$ or $\mathrm{R}_{2}=\mathrm{Me},{ }^{t} \mathrm{Bu}, \mathrm{CMe}_{2} \mathrm{Ph}$ ) were synthesised, according to modified literature procedures, from substituted phenols. The 2,4-dialkyl phenols were first orthobrominated with elemental bromine in dichloromethane, then reacted with allyl bromide under basic conditions in acetone. This was followed by the dropwise addition of ${ }^{n} \mathrm{BuLi}$ and then 


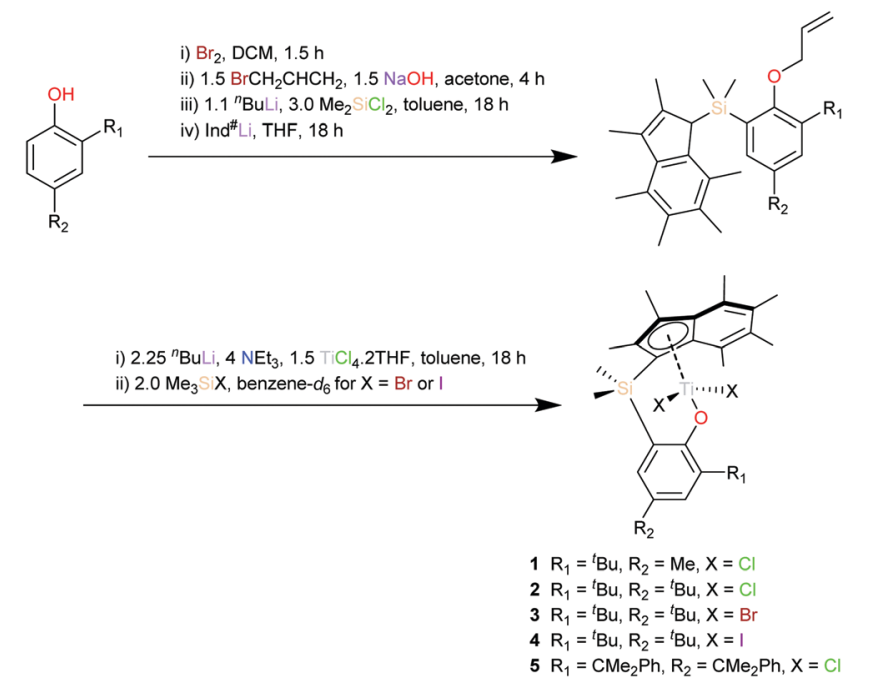

Scheme 1 Synthesis of PHENI* complexes $\left.{ }^{\mathrm{Me}_{2}} \mathrm{SB}^{t}{ }^{t} \mathrm{Bu}^{*} \mathrm{Me}^{\mathrm{ArO}}, \mathrm{I}^{*}\right) \mathrm{TiCl}_{2}$ (1),

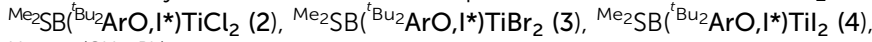
$\mathrm{Me}_{2} \mathrm{SB}\left({ }^{\left(\mathrm{CMe}_{2} \mathrm{Ph}\right)_{2}} \mathrm{ArO}^{\prime *}\right) \mathrm{TiCl}_{2}(\mathbf{5})$.

reaction with dichlorodimethylsilane in toluene to afford the chlorosilane products in good yields (57-80\%). Stirring these intermediates with $\operatorname{Ind}^{\#} \mathrm{Li}\left(\operatorname{Ind}^{\#}=\mathrm{C}_{9} \mathrm{Me}_{6} \mathrm{H}\right)$ in THF overnight afforded the allylprotected $\mathrm{PHENI}^{*}$ proligands, ${ }^{\mathrm{Me}}{ }_{2} \mathrm{SB}\left({ }^{\mathrm{R}_{1} \mathrm{R}_{2}}\right.$ ArOAllyl,I, $\left.{ }^{*}\right) \mathrm{H}\left(\left(\mathrm{C}_{9} \mathrm{Me}_{6} \mathrm{H}\right)\right.$ $\left.\mathrm{Me}_{2} \mathrm{Si}\left(2-\mathrm{R}_{1}-4-\mathrm{R}_{2}-\mathrm{C}_{6} \mathrm{H}_{2} \mathrm{OCH}_{2} \mathrm{CHCH}_{2}\right) ; \mathrm{I}^{*}=\mathrm{C}_{9} \mathrm{Me}_{6}\right)$ in $75 \%$ yield on multigram scales (Scheme 1).

Titanium dichloride complexes, ${ }^{{ }^{\mathrm{Me}} 2}{ } \mathrm{SB}\left({ }^{\mathrm{R}_{1} \mathrm{R}_{2}} \mathrm{ArO}, \mathrm{I}^{*}\right) \mathrm{TiCl}_{2}$ $\left(\left\{\left(\eta^{5}-\mathrm{C}_{9} \mathrm{Me}_{6}\right) \mathrm{Me}_{2} \mathrm{Si}\left(2-\mathrm{R}_{1}-4-\mathrm{R}_{2}-\mathrm{C}_{6} \mathrm{H}_{2} \mathrm{O}\right)\right\} \mathrm{TiCl}_{2} ; \mathrm{R}_{1}, \mathrm{R}_{2}=\mathrm{Me},{ }^{t} \mathrm{Bu}\right.$, or $\mathrm{CMe}_{2} \mathrm{Ph}$ ), were synthesised using in situ deprotection, deprotonation, and complexation - reacting the proligands with ${ }^{n} \mathrm{BuLi}$, followed by $\mathrm{TiCl}_{4} \cdot 2 \mathrm{THF}$ in toluene gave brick-red microcrystal-

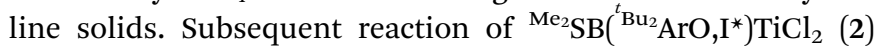
with bromotrimethylsilane or iodotrimethylsilane in benzene$d_{6}$ resulted in the rapid quantitative formation of the dibromo (3) and diiodo (4) complexes respectively.

Crystals of 2 suitable for single crystal X-ray diffraction studies were grown from a saturated pentane solution at $-30{ }^{\circ} \mathrm{C}$ (Fig. 1). The solid-state structure of 2 is significantly more distorted than the indenyl-PHENICS complex $6\left({ }^{\mathrm{Me}}{ }_{2} \mathrm{SB}\left({ }^{(\mathrm{Bu}, \mathrm{Me}} \mathrm{ArO}, \mathrm{Ind}\right) \mathrm{TiCl}_{2} ; \quad\left\{\left(\eta^{5}-\mathrm{C}_{9} \mathrm{H}_{6}\right) \mathrm{Me}_{2} \mathrm{Si}\left(2-{ }^{\mathrm{C}} \mathrm{Bu}-4-\mathrm{Me}^{-\mathrm{C}_{6}} \mathrm{H}_{2} \mathrm{O}\right)\right\}\right.$ $\mathrm{TiCl}_{2}$; Ind $=\mathrm{C}_{9} \mathrm{H}_{6}$ ), first reported by Hanaoka et al., as defined by the larger torsion angle $\mathrm{C}(1)-\mathrm{Si}(1)-\mathrm{C}(23)-\mathrm{C}(18)=35.89(1)^{\circ}\left(c f .11 .75^{\circ}\right.$ for the indenyl complex) and a smaller $\mathrm{I}^{*}$-ArO dihedral angle $\left(48.57^{\circ}\right.$ cf. $60.85^{\circ}$ for the indenyl complex).

PHENI $^{*}$ complexes 1-5 and the indenyl-PHENICS complex 6 were supported on solid polymethylaluminoxane (sMAO) according to standard immobilisation procedures, ${ }^{7}$ with $\left[\mathrm{Al}_{\mathrm{sMAO}}\right]_{0} /[\mathrm{Ti}]_{0}=200$, to afford $\mathbf{1}_{\text {SMAO }}-\mathbf{6}_{\text {SMAO }}$. Additionally, 2 was immobilised on MAOmodified silica (SSMAO) (silica was precalcined at $600{ }^{\circ} \mathrm{C}$ for $6 \mathrm{~h}$ and treated with $40 \mathrm{wt} \% \mathrm{MAO}$ ) and an MAO-modified layered double hydroxide (LDHMAO) (LDH was 1-hexanol washed $\mathrm{Mg}_{3} \mathrm{Al}-\mathrm{CO}_{3} \mathrm{LDH}$, calcined at $150{ }^{\circ} \mathrm{C}$ for $6 \mathrm{~h}$, and treated with $40 \mathrm{wt} \% \mathrm{MAO}$ ), both with $\left[\mathrm{Al}_{\mathrm{MAO}}\right]_{0} /[\mathrm{Ti}]_{0}=200$, to afford $2_{\text {SSMAO }}$ and $2_{\text {IDHMAO }}$ respectively.

Preliminary solution-phase polymerisations were performed with 2 under ethylene ( 2 bar), with $49 \mathrm{~mL}$ hexanes and $1 \mathrm{~mL}$

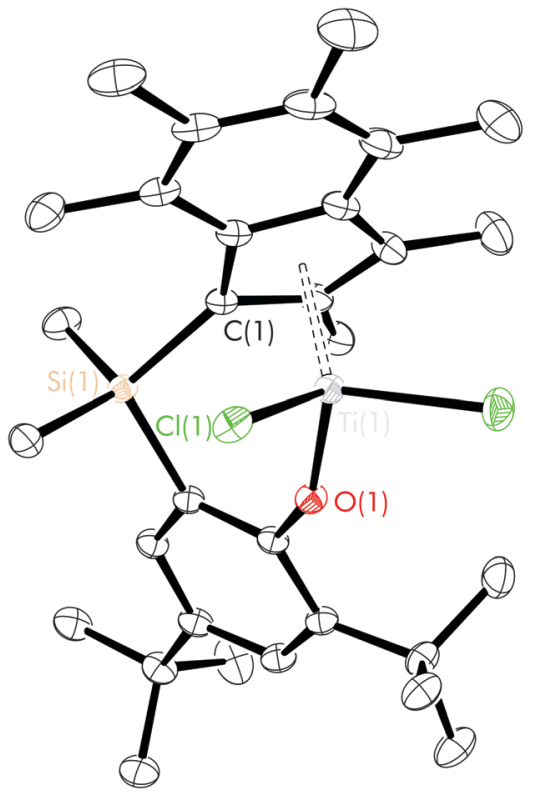

Fig. 1 Solid-state molecular structure of $\left.{ }^{\mathrm{Me}_{2} \mathrm{SB}}{ }^{t}{ }^{t}{ }^{2} \mathrm{ArO}_{1} \mathrm{I}^{*}\right) \mathrm{TiCl}_{2}$ (2). Ellipsoids drawn at $30 \%$ probability and all hydrogen atoms omitted for clarity.

toluene, $414 \mu \mathrm{g}$ complex and an $\mathrm{Al}$ : Ti ratio (MAO: complex) of 1000:1 for 5 minutes. The highest activity was recorded at $70{ }^{\circ} \mathrm{C}\left(4.8 \times 10^{6} \mathrm{~g}_{\mathrm{PE}} \mathrm{mol}_{\mathrm{Ti}}{ }^{-1} \mathrm{~h}^{-1} \mathrm{bar}^{-1}\right)$. As is commonly seen for solution-phase polymerisations, the PE formed with a highly aggregated morphology which caused reactor fouling.

Slurry-phase ethylene polymerisation studies were conducted with $10 \mathrm{mg}$ of supported catalyst in $50 \mathrm{~mL}$ hexanes with 2 bar monomer pressure for 30 minutes and $150 \mathrm{mg}$ tri-iso-butylaluminium (TIBA)

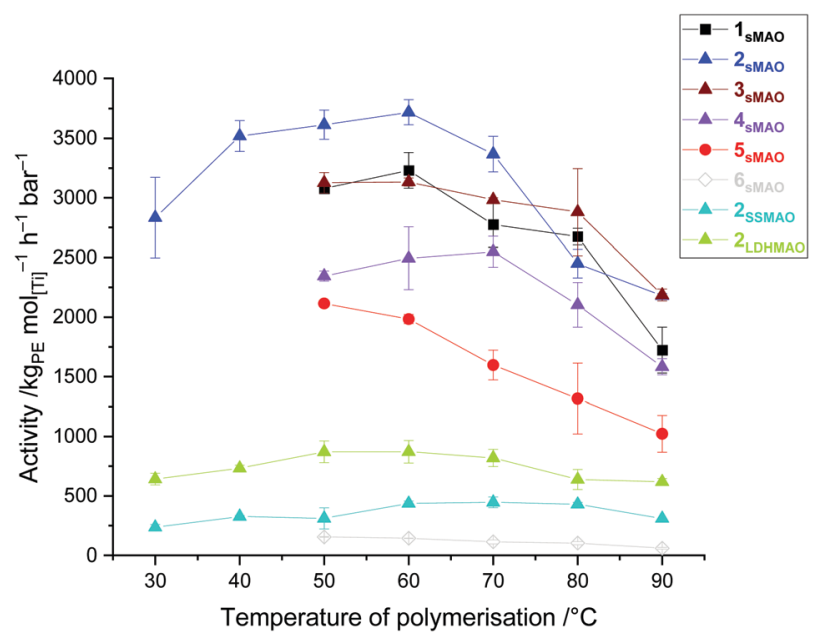

Fig. 2 Slurry-phase ethylene polymerisation activity as a function of the temperature of polymerisation using sMAO-supported ${ }^{\mathrm{Me}} 2 \mathrm{SB}\left({ }^{\mathrm{tBu}, \mathrm{Me}} \mathrm{ArO}, 1^{*}\right)$ -

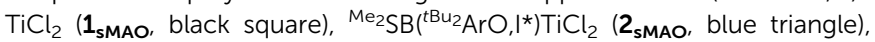

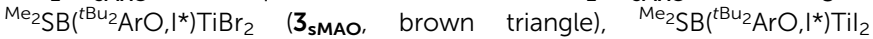

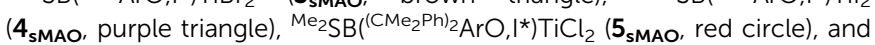

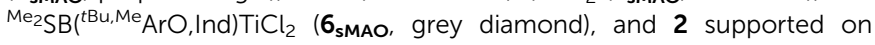
SSMAO (2 SSMAO, teal triangle) and LDHMAO (2 LDHMAO, green triangle). Polymerisation conditions: $10 \mathrm{mg}$ catalyst, 2 bar ethylene, $50 \mathrm{~mL}$ hexanes, 30 minutes, and $150 \mathrm{mg}$ tri-iso-butylaluminium. 


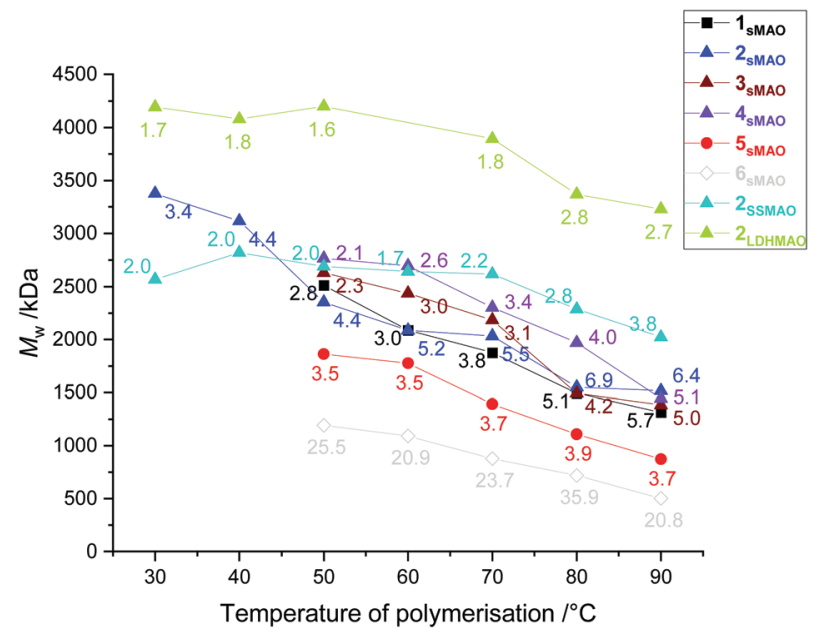

Fig. 3 Weight-average molecular weight $\left(M_{w}\right)$, with PDIs $\left(M_{w} / M_{n}\right)$ annotated, of polyethylene synthesised using sMAO-supported ${ }^{\mathrm{Me}}{ }_{2 \mathrm{SB}}\left({ }^{\mathrm{Bu}}, \mathrm{Me}^{\mathrm{A}} \mathrm{ArO}, I^{*}\right) \mathrm{TiCl}_{2}$ ( $\mathbf{1}_{\text {sMAO }}$ black square), ${ }^{\mathrm{Me}_{2}} \mathrm{SB}\left({ }^{\mathrm{B} \mathrm{Bu}_{2}} \mathrm{ArO} \mathrm{I}^{*}\right) \mathrm{TiCl}_{2} \quad\left(\mathbf{2}_{\text {sMAO, }}\right.$ blue triangle), $\mathrm{Me}_{2} \mathrm{SB}\left({ }^{t \mathrm{Bu}_{2}} \mathrm{ArO}, I^{*}\right) \mathrm{TiBr}_{2} \quad\left(3_{\mathrm{SMAO}}\right.$ brown triangle), ${ }^{\mathrm{Me}_{2}} \mathrm{SB}\left({ }^{\mathrm{B} \mathrm{Bu}_{2}} \mathrm{ArO}, I^{*}\right) \mathrm{Til}_{2}$

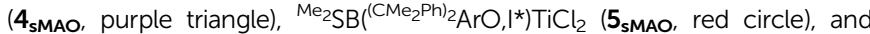
$\mathrm{Me}_{2} \mathrm{SB}\left({ }^{\mathrm{tBu}}, \mathrm{Me} \mathrm{ArO}, \mathrm{Ind}\right) \mathrm{TiCl}_{2}\left(\boldsymbol{6}_{\mathrm{sMAO}}\right.$, grey diamond), and $\mathbf{2}$ supported on SSMAO

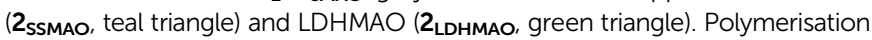
conditions: $10 \mathrm{mg}$ catalyst, 2 bar ethylene, $50 \mathrm{~mL}$ hexanes, 30 minutes, and $150 \mathrm{mg}$ tri-iso-butylaluminium.

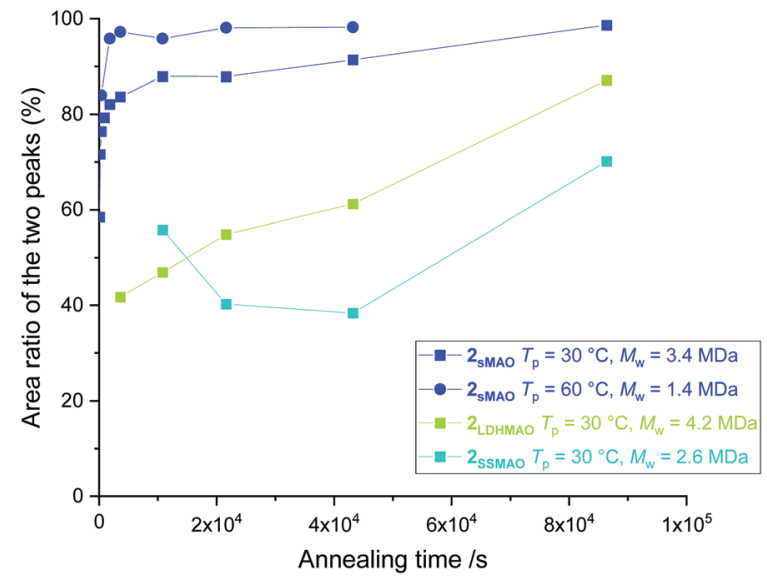

Fig. 4 Evolution of the normalised area of DSC peaks as a function of annealing time.

acting as a co-catalytic initiator and scavenger (Fig. 2). When supported on SMAO, all PHENI* complexes $\mathbf{1}_{\text {SMAO }}-\mathbf{5}_{\text {sMAO }}$ demonstrated significantly higher activity compared to $\mathbf{6}_{\text {sMAO }}$, with $\mathbf{2}_{\text {SMAO }}$ demonstrating the highest activity of $3.7 \times 10^{6} \mathrm{~g}_{\mathrm{PE}} \mathrm{mol}_{\mathrm{Ti}}^{-1} \mathrm{~h}^{-1} \mathrm{bar}^{-1}$ at a polymerisation temperature $\left(T_{\mathrm{p}}\right)$ of $60{ }^{\circ} \mathrm{C}$ compared with $0.1 \times$ $10^{6} \mathrm{~g}_{\mathrm{PE}} \mathrm{mol}_{\mathrm{Ti}}{ }^{-1} \mathrm{~h}^{-1} \mathrm{bar}^{-1}$ for $\mathbf{6}_{\mathrm{sMAO}}$ under the same conditions. The observation that both $\mathbf{1}_{\mathbf{S M A O}}$ and $\mathbf{5}_{\text {SMAO }}$ display lower activities than $\mathbf{2}_{\text {sMaO }}$ suggests a limitation to the hypothesis, proposed by Nabika et al., that more sterically demanding phenoxide ligands resulted in higher polymerisation activities. ${ }^{13}$ Both $\mathbf{2}_{\text {SMAO }}$ and $\mathbf{3}_{\text {SMAO }}$ show consistently higher activities than $\mathbf{4}_{\text {SMAO }}$, though the difference between $\mathbf{2}_{\text {SMAO }}$ and $\mathbf{3}_{\text {SMAO }}$ decreases at higher polymerisation temperatures,

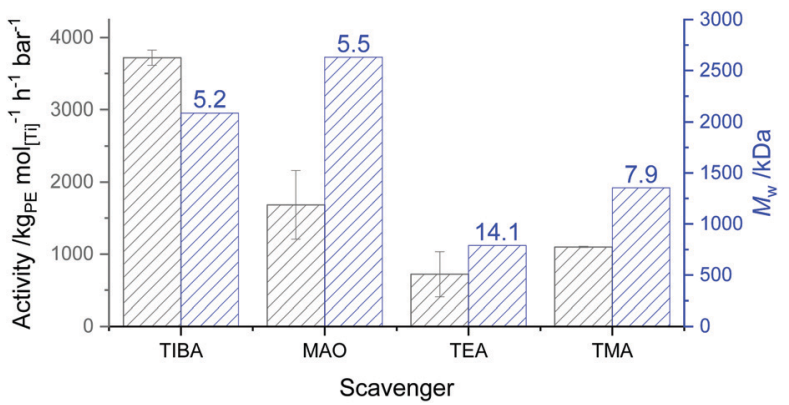

Fig. 5 Slurry-phase polymerisation activity of, and weight-average molecular weight (with PDIs annotated) of polyethylene produced using $\mathrm{Me}_{2} \mathrm{SB}\left({ }^{{ }^{\mathrm{B}} \mathrm{Bu}_{2}} \mathrm{ArO}, \mathrm{I}^{*}\right) \mathrm{TiCl}_{2}$ supported on SMAO $\left(\mathbf{2}_{\text {sMAO }}\right.$ ) with varying aluminium cocatalytic scavengers. Polymerisation conditions: $10 \mathrm{mg}$ catalyst, 2 bar ethylene, $50 \mathrm{~mL}$ hexanes, $60{ }^{\circ} \mathrm{C}, 30$ minutes, and $[\mathrm{Al}]_{0} /[\mathrm{Ti}]_{0}=1000$.

being within error of each other at $T_{\mathrm{p}} \geq 80^{\circ} \mathrm{C}$. When immobilised on MAO-modified silica (SSMAO) and MAO-modified LDH (LDHMAO), $2_{\text {SSMAO }}$ and $2_{\text {IDHMAO }}$ show significantly lower activities than SMAO. With all three supports, the polymer morphology benefits from the templating effect of the support in creating uniform, dispersed particles which are free-flowing with no reactor fouling.

Polyethylene synthesised using slurry-phase supported PHENI* complexes 1-6 was analysed by gel permeation chromatography (GPC); the GPC data demonstrates that PHENI*based catalysts produce UHMWPE (Fig. 3). In all cases, $M_{\mathrm{w}}$ decreases with increasing polymerisation temperature. The molecular weight of PE produced using $2_{\text {SMAO }}$ ranges from $1.5 \mathrm{MDa}$ at $90{ }^{\circ} \mathrm{C}$ to $3.4 \mathrm{MDa}$ at $30{ }^{\circ} \mathrm{C}$, greater than both $\mathbf{1}_{\text {sMAO }}$ and $\mathbf{5}_{\text {SMAO }}$, and a substantial increase with respect to the indenyl-PHENICs complex $\mathbf{6}_{\text {sMAO. }} M_{\mathrm{w}}$ was broadly similar between the halide complexes $\mathbf{2}_{\mathbf{S M A O}}, \mathbf{3}_{\mathbf{s M A O}}$, and $\mathbf{4}_{\mathbf{s M A O}}$. At $T_{\mathrm{p}}=60{ }^{\circ} \mathrm{C}, M_{\mathrm{w}}$ of PE synthesised by $\mathbf{4}_{\text {sMao }}$ was $2.7 \mathrm{MDa}, 11 \%$ greater than the bromide complex, in turn $17 \%$ greater than the chloride, though at higher polymerisation temperatures the values became similar to each other. The polydispersity of the PE produced by the PHENI*-based catalysts is narrow, and significantly improved compared to $\mathbf{6}_{\text {sMAO }}$, where a bimodal distribution $\left(M_{\mathrm{w}} / M_{\mathrm{n}}=20.8-35.9\right)$ is indicative of a departure from single-site catalytic behaviour. The molecular weights of the PE were up to $113 \%$ higher when 2 was immobilised on LDHMAO than SMAO, reaching $4.2 \mathrm{MDa}$ at $T_{\mathrm{p}}=50^{\circ} \mathrm{C}$ and these high values were maintained at higher temperatures - 3.2 MDa at $90{ }^{\circ} \mathrm{C}$. While $2_{\text {SSMao }}$ produced lower $M_{\mathrm{w}} \mathrm{PE}$ than $2_{\text {sMAO }}$ at low temperatures, it was able to maintain high molecular weights at higher temperatures, only decreasing below $2.5 \mathrm{MDa}$ at $80{ }^{\circ} \mathrm{C}$ The temperature dependence of the $\mathrm{PE} M_{\mathrm{W}}$ is far less significant for PHENI*-based catalysts supported on either LDHMAO or SSMAO compared to those supported on SMAO, and is approximately constant for $30{ }^{\circ} \mathrm{C} \leq T_{\mathrm{p}} \leq 70{ }^{\circ} \mathrm{C}$ in both cases.

The nature of the polyethylene was analysed by differential scanning calorimetry (DSC). At a heating rate of $20 \mathrm{~K} \mathrm{~min}^{-1}$ all samples displayed a melting endotherm on the second heating cycle at $133-135{ }^{\circ} \mathrm{C}$, with crystallinities of $68-83 \%$. Nascent polymers were subjected to a DSC annealing protocol established by Rastogi et al. to determine the presence of chain entanglements (Fig. 4). ${ }^{18}$ 
While PE produced in solution-phase polymerisations was clearly highly entangled, slurry-phase polymerisations using sMAO led to the production of substantially disentangled UHMWPE (disUHMWPE) as evidenced by the rapid formation of two melting peaks (at approximately 135 and $142{ }^{\circ} \mathrm{C}$ ), with the low temperature peak increasing at the expense of the high temperature peak as annealing time is increased. The high melting peak results from remaining nascent crystals while the low melting peak arises from the melt-crystallised portion formed from sequential chain detachment during annealing. For a given $M_{\mathrm{w}}$ a more rapid increase in the normalised area of the low melting peak is indicative of a more disentangled polymer. ${ }^{22}$ This is in contrast to the behaviour observed for commercial entangled UHMWPE synthesised using Ziegler-Natta catalysts, which has been shown by Rastogi et al. to have a significantly different response to annealing, with the low melting peak increasing in area at a dramatically slower rate. ${ }^{18,23}$

Several alkylaluminium species, $\mathrm{R}_{3} \mathrm{Al}\left(\mathrm{R}=\mathrm{Me}, \mathrm{Et},{ }^{\mathrm{i}} \mathrm{Bu}\right)$ and MAO, were investigated as co-catalytic scavengers with 2 sMAO (Fig. 5). It was found that activity increased in the order TEA $<$ TMA $<$ MAO $<$ TIBA, with 2 sMAO/TIBA having more than twice the activity as $\mathbf{2}_{\text {sMAO}} /$ MAO. However, while polymer molecular weight was high in all cases, there was a significant low molecular weight fraction observed with both TEA and TMA, resulting in larger PDIs and lower $M_{\mathrm{w}}$ values. This is presumed to be due to the one-electron reduction of some titanium centres in addition to increased chain transfer to aluminium in these cases.

In conclusion, new ansa-permethylindenyl-phenoxide (PHENI*) complexes have been synthesised and fully characterised. Heterogeneous catalytic polymerisation systems have been developed utilising a range of inorganic supports for the slurry-phase polymerisation of ethylene. The PHENI* complexes have been found to be significantly more active than the indenyl-PHENICS analogues, as well as producing polyethylene with narrower molecular weight distributions. SMAO- ${ }^{\mathrm{Me}_{2}} \mathrm{SB}\left({ }^{\left(\mathrm{Bu}_{2} \mathrm{ArO}, \mathrm{I}^{*}\right) \mathrm{TiCl}_{2}} \quad\left(2_{\text {sMAO }}\right)\right.$ had the highest slurry-phase activity of the complexes studied $(3.7 \times$ $\left.10^{6} \mathrm{~g}_{\mathrm{PE}} \mathrm{mol}_{\mathrm{Ti}}^{-1} \mathrm{~h}^{-1} \mathrm{bar}^{-1}\right)$. Additionally, these PHENI ${ }^{*}$-based systems have been demonstrated to produce substantially disentangled UHMWPE when supported on solid MAO, with molecular weights up to 4.2 MDa when supported on an MAO-modified LDH.

C. G. C. R., J.-C. B., Z. R. T. would like to thank SCG Chemicals Co., Ltd (Thailand) for financial support. We also thank Ms Liv Thobru, Ms Sara Rund Herum, and Ms Rita Jenssen (Norner AS) for running GPC analysis; Prof. Vincenzo
Busico for the use of HTExplore (University of Naples); and $\mathrm{Mr}$ Alessio Mingione and Prof. Roberta Cipullo (HTExplore) for running high-throughput polymerisation experiments and polymer analysis.

\section{Conflicts of interest}

There are no conflicts to declare.

\section{Notes and references}

1 W. Kaminsky, J. Chem. Soc., Dalton Trans., 1998, 1413-1418.

2 P. Wongwaiwattanakul and B. Jongsomjit, Catal. Commun., 2008, 10, 118-122.

3 K. Soga and M. Kaminaka, Makromol. Chem., 1993, 194, 1745-1755.

4 T. Pothirat, B. Jongsomjit and P. Praserthdam, Catal. Commun., 2008, 9, 1426-1431.

5 C. P. Chen, M. S. Yang, Q. Wang, J. C. Buffet and D. O'Hare, J. Mater. Chem. A, 2014, 2, 15102-15110.

6 G. E. Hickman, C. M. R. Wright, A. F. R. Kilpatrick, Z. R. Turner, J.-C. Buffet and D. O'Hare, Mol. Catal., 2019, 468, 139-147.

7 J.-C. Buffet, N. Wanna, T. A. Q. Arnold, E. K. Gibson, P. P. Wells, Q. Wang, J. Tantirungrotechai and D. O'Hare, Chem. Mater., 2015, 27, 1495-1501.

8 A. F. R. Kilpatrick, J.-C. Buffet, P. Nørby, N. H. Rees, N. P. Funnell, S. Sripothongnak and D. O'Hare, Chem. Mater., 2016, 28, 7444-7450.

9 T. A. Q. Arnold, Z. R. Turner, J.-C. Buffet and D. O'Hare, J. Organomet. Chem., 2016, 822, 85-90.

10 A. F. R. Kilpatrick, N. H. Rees, S. Sripothongnak, J.-C. Buffet and D. O'Hare, Organometallics, 2018, 37, 156-164.

11 H. Braunschweig and F. M. Breitling, Coord. Chem. Rev., 2006, 250, 2691-2720.

12 J. Klosin, P. P. Fontaine and R. Figueroa, Acc. Chem. Res., 2015, 48, 2004-2016.

13 M. Nabika, H. Katayama, T. Watanabe, H. Kawamura-Kuribayashi, K. Yanagi and A. Imai, Organometallics, 2009, 28, 3785-3792.

14 H. Hanaoka, T. Hino, M. Nabika, T. Kohno, K. Yanagi, Y. Oda, A. Imai and K. Mashima, J. Organomet. Chem., 2007, 692, 4717-4724.

15 H. Katayama, M. Nabika, A. Imai, A. Miyashita, T. Watanabe, H. Johohji, Y. Oda and H. Hanaoka, Intl. Pat., 1997, WO9703992A1.

16 T. Senda, H. Hanaoka, S. Nakahara, Y. Oda, H. Tsurugi and K. Mashima, Macromolecules, 2010, 43, 2299-2306.

17 M. Hussain, R. A. Naqvi, N. Abbas, S. M. Khan, S. Nawaz, A. Hussain, N. Zahra and M. W. Khalid, Polymers, 2020, 12, 323.

18 D. Romano, N. Tops, E. Andablo-Reyes, S. Ronca and S. Rastogi, Macromolecules, 2014, 47, 4750-4760.

19 D. R. Lippits, S. Rastogi, G. W. H. Hohne, B. Mezari and P. C. M. M. Magusin, Macromolecules, 2007, 40, 1004-1010.

20 S. Rastogi, Y. Yao, S. Ronca, J. Bos and J. van der Eem, Macromolecules, 2011, 44, 5558-5568.

21 K. Patel, S. H. Chikkali and S. Sivaram, Prog. Polym. Sci., 2020, 109, 101290.

22 A. Pandey, A. Toda and S. Rastogi, Macromolecules, 2011, 44, 8042-8055.

23 S. Rastogi, D. R. Lippits, G. W. M. Peters, R. Graf, Y. Yao and H. W. Spiess, Nat. Mater., 2005, 4, 635-641. 